\title{
Developing the Scale of Problem-Solving Skills for Secondary School-Aged Deaf and Hard of Hearing Students
}

\author{
Esra Çoban Budak ${ }^{1}$, Arzu Deveci Topal ${ }^{1 *}$, Aynur Kolburan Geçer ${ }^{1}$ \\ ${ }^{1}$ Kocaeli University, Izmit, TURKEY
}

*Corresponding Author: arzudevecit@gmail.com

Citation: Çoban Budak, E., Deveci Topal, A. and Kolburan Geçer, A. (2018). Developing the Scale of Problem-Solving Skills for Secondary School-Aged Deaf and Hard of Hearing Students. Pedagogical Research, 3(1), 04. https://doi.org/10.20897/pr/86824

Published: April 2, 2018

\begin{abstract}
The scales for measuring problem-solving skills developed for students without impairment do not seem to include essential criteria for measuring the problem-solving skills of secondary school-aged students with hearing impairment. In order to compensate for these lacks and accurately measure these students' problemsolving skills, a scale of problem-solving skills proposed by secondary school curriculums has been developed. The scale includes texts complying with sign language, its visual components are advanced and the use of verbal expressions is decreased for the secondary school-aged deaf and hard-of-hearing students. The data was collected using the Scale of Problem Solving for the Deaf and Hard of Hearing (SPSDH) and a personal information form. The sample of this research consisted of 73 students. In order to ensure the construct validity of the test, item analysis was carried out. The outcome of the formula showed that KR20 internal consistency coefficient was .704 for 8 items. According to the item analysis, the average item difficulty and discrimination indices of the test were calculated as 0.46 and 0.63 respectively. These results show that the items able to distinguish the students in terms of their problem-solving skills. The findings obtained from the present study reveal that the SPSDH is a valid and reliable measurement tool that can be used to determine the problem-solving skills of secondary school-aged deaf and hard-of-hearing students.
\end{abstract}

Keywords: secondary school-aged, deaf and hard-of-hearing students, problem-solving skills

\section{INTRODUCTION}

In a world faced with global financial crises, ever-changing information and education contexts, progressively complex community structures and rapid technological development, it is more important than ever for individuals to develop and improve their problem-solving skills. Problem solving is to apply previously acquired knowledge, skills and understanding to an unfamiliar situation (Krulik and Rudnick, 1988). It is a complicated process which includes cognitive, sensory and behavioural coping strategies. According to Polya (1957), understanding the problem, making a plan, carrying out the plan and looking back on the work are the abilities that enable individuals to solve problems effectively.

Problem solving can be considered a facet of thinking as a whole (Smiley et al., 2009). Marzono et al. (1988) proposes the following four-dimensional frame about thinking: metacognition, critical/creative thinking, thinking processes and skills. In order to be able to solve a problem, the person must improve their skills of data collecting and analysing. Thornton (1995) suggests that the process applied in problem solving is dependent on the child's acquired knowledge base. The affluence of the child's knowledge facilitates the problem-solving process. Problem solving is a learnable process and individuals can be helped through education for improving problem-solving skills to overcome the difficulties they encounter. The main objective of teaching is to enhance students' problemsolving skills by helping them use their mental abilities (Gagne, 1980). So, problem-solving training will significantly 
contribute other aspects of students' lives such as self-confidence, communication skills, effective decision-making, self-respect and social competence.

The acquisition of problem-solving skills is as vital of a capability for people with impairments as it is for those without impairments. Tufekcioglu (2005) states that hearing-impaired students are less successful in solving problems than typical students and although they learn verbal skills more easily, they are more likely to have difficulty with problems given in sentences compared to their non-impaired peers. She explains that this is due to the verbal and written language skills of the hearing impaired students not being at the same level as their hearing peers. In another study by Luckner and McNeill (1994), it was determined that hard-of-hearing or hearing impaired students had underdeveloped problem-solving skills compared to students with typical hearing. The research into the issue has revealed that hearing loss has an effect on a child's language, social and cognitive development and when one of these domains is delayed, another is affected as well (Laurent, 2014). Luckner and Mcneil (1994) claim that children who have underdeveloped linguistic abilities are likely to have difficulty using mental manipulation when trying to solve multi-dimensional problems due to an insufficient ability to communicate. Laurent (2014) utilized the tasks of 'The tower of Hanoi' and 'Twenty Questions' in a study carried out to determine the problemsolving skills of hearing-impaired students and found that problem-solving skills of students who were hard of hearing or hearing impaired tended to fall on the lower end of the average range, where the typical population standardized the average range.

As deaf and hard-of-hearing students are not able to listen to what happens around them, the possibility of learning which method to use for solving a problem diminishes for them. So as to minimise these deficits, children can be trained in how to gain the abilities of problem solving and analytical thinking. To make it easier to solve a problem, the process may be concretized by drawing figures or schemas related to the problem. Therefore, graphic symbols can be utilized as an alternative communication tool for people who have difficulties in language, speaking and learning (Karal et al., 2014).

Various scales can be applied to determine students' problem-solving skills. Traditional scales of problem solving are given verbally and the replies are received so as well (Tüfekçioğlu, 2005). Due to lack of experience (stimuli) inadequate education, and underdeveloped verbal and written linguistic abilities of people with hearing impairment, it is hard for them to read and understand these kinds of scales and consequently it is not possible to perform valid measurements. It has been recognized that scales of problem solving developed for students without impairment do not provide essential criteria for measuring the problem-solving skills of secondary school-aged students with hearing impairment. Developing a scale of problem solving proposed by secondary school curriculums and which includes texts compliant with sign language, advanced visual components and fewer verbal expressions for secondary school-aged deaf and hard-of-hearing students will compensate for an important deficiency in the field. Thus, it will be possible to identify these students' problem-solving skills at an early age and this will guide experts and educators studying in the field to evaluate the existing condition.

\section{METHOD}

The objective of the present study is to develop a measurement tool aimed at measuring the level of the problem-solving skills of secondary school-aged deaf and hard-of-hearing students. The study used the participation of 73 students from Gazanfer Bilge Hearing Impaired Secondary School in Kocaeli and Duyum Hearing Impaired Secondary School in Nilufer, Bursa, who were enrolled in the 2015-2016 academic year and contacted via organisations for the hearing and visually impaired. The participants consisted of 42 males $(58 \%)$ and 31 females $(42 \%)$ at the secondary school level (Table 1).

Table 1. Distribution of the students by grade and gender

\begin{tabular}{lccccc}
\hline Gender/class & $\mathbf{5 .}$ & $\mathbf{6 .}$ & $\mathbf{7 .}$ & $\mathbf{8 .}$ & Total \\
\hline Male & 7 & 8 & 12 & 15 & 42 \\
\hline Female & 6 & 3 & 6 & 16 & 31 \\
\hline Total & 13 & 11 & 18 & 31 & 73 \\
\hline
\end{tabular}

While collecting data from the students, they were given the measurement tool and instructed to read it. Despite the fact that most of the students read what was written, their teachers had to explain the scale via sign language as they did not understand what it meant.

\section{Data Collection Tool}

In this study, the scale of problem-solving skills developed for students in the 4th, 5th, 6th, 7th and 8th grades by Sezgin (2009) has been modified for secondary school-aged deaf and hard-of-hearing students after receiving expert opinions and reviewing the literature. Sezgin took expert opinions for construct validity of the scale and 
calculated the KR-20 internal consistency coefficient for the scale's reliability in her study. According to the statistical calculations performed, the KR-20 internal consistency coefficient of the scale was calculated as 0.76 and as an outcome of reliability coefficient which meant consistency and was figured out by using the test-retest method, correlation coefficient was calculated as .94

While re-organizing this study, verbal expressions were decreased and problems were simplified in the scale, also pictures were used where possible in accordance with information about the general condition of the students gathered from teachers of the deaf and hard of hearing. Then a pre-implementation was carried out with 10 students, sections in which the students had difficulty were diagnosed and the scale was reorganized with guidance of the teachers of the deaf and hard of hearing.

According to Büyüköztürk (2003), in order to ensure the content validity of a scale, one of the most applied methods for testing this kind of validity is taking expert opinion. The scale was finalized by taking the opinions of three experts from the department of Assessment and Evaluation and 5 teachers, 3 of which were teachers of the deaf and hard of hearing and 2 of which were Turkish language teachers working in Schools for the Hearing Impaired so that the questions in the measurement tool were suitable for the content and student population. The Scale of Problem Solving for The Deaf and Hard-of-Hearing (SPSDH) consisted of 8 items about figuring out the experiences of a family of three people while planning a holiday together and deciding which questions they needed to reply to in order to find a solution. While evaluating the responses, the right answer was scored with 1 and the wrong with 0 . The highest score that could be obtained from the scale was 8 .

In the analysis of data, SPSS 16.0 was used for frequency analysis and reliability, and a t-test was applied to find the difference between the super and sub groups. Item discrimination and difficulty indices were calculated with an electronic spreadsheet programme.

\section{Findings Related to Validity and Reliability Studies of the Test}

Content and construct validities were examined within the scope of validity studies in the present research. Calculated for the outcomes of the SPSDH, the Cronbach $\alpha$ reliability coefficient was found as 0.7. With item analysis, the average indices of item difficulty and discrimination of the test were calculated as 0.46 and 0.63 respectively. Some statistical data regarding the item analysis in the outcomes of the scale of problem-solving skills for secondary school-aged deaf and hard-of-hearing students is given in Table 2 .

Table 2. Statistics for SPSDH

\begin{tabular}{ll}
\hline Number of Questions & 8 \\
\hline Number of people who applied & 73 \\
\hline Mean & 3,367 \\
\hline Standard deviation & 2,12 \\
\hline Skewness &, 696 \\
\hline Kurtosis & $-0,308$ \\
\hline Cronbach alpha & 0,7 \\
\hline Average item difficulty & 0,46 \\
\hline Average item distinctiveness & 0,63 \\
\hline
\end{tabular}

As a result of the data analysis, the skewness coefficient was found to be 0.696 and the kurtosis coefficient was -0.308 , which meant that the distribution was slightly left-skewed and kurtosis Howevert the distribution can be said to be typical as these deviations were between the range of $-1,+1$.

To ensure the construct validity of the test items, item analysis was performed. Item analysis, basically, is applied in order to choose the items that will be included in a test that should have specific qualities. The item analysis results are shown in Table 3. The data related to the correct answers in Table 4 was used while calculating item difficulty and discrimination.

Table 3. The number of correct answers to questions in super and sub groups according to item analysis results

\begin{tabular}{|c|c|c|c|c|c|c|c|c|}
\hline Analysis for 73 students & M1 & M2 & M3 & M4 & M5 & M6 & M7 & M8 \\
\hline Sub group $\% 27(\mathrm{~N}=20)$ & 0 & 1 & 3 & 5 & 0 & 4 & 6 & 4 \\
\hline Top group $\% 27(\mathrm{~N}=20)$ & 12 & 9 & 20 & 20 & 14 & 14 & 16 & 19 \\
\hline
\end{tabular}

Table 4. Item difficulty and discrimination indices of the items in the SPSDH

\begin{tabular}{lcccccccc}
\hline Item no & M1 & M2 & M3 & M4 & M5 & M6 & M7 & M8 \\
\hline Item difficulty index (p) & 0,30 & 0,25 & 0,58 & 0,63 & 0,35 & 0,45 & 0,55 & 0,58 \\
\hline Item discrimination index $(\mathrm{r})$ & 0,60 & 0,40 & 0,85 & 0,75 & 0,70 & 0,50 & 0,50 & 0,75 \\
\hline
\end{tabular}


Kuder Richardson Formula 20 was used to estimate the difficulty level of each item in the measurement tool and the reliability of a calculated test. According to this formula, the KR-20 internal consistency coefficient was found to be .704 for 8 items. This proved that the measurement tool measured the problem-solving skills with eight items by $70 \%$.

The analysis results of item difficulty and discrimination that were found by method of item analysis of $27 \%$ sub and up group. The value of the item difficulty index ranges between 0 and +1 : the higher the value, the easier the item. If the index of item difficulty is 0.50, the question is accepted as moderate (Attlgan et al., 2009). The index of item discrimination ranges between -1 and +1 . Negative index of item discrimination means that the individuals whose total test grades are high have obtained low scores from questions, in other words, the students who have succeeded on the whole test have answered the question less correctly and it discriminates the individuals in respect to the features of the items expected to be measured (Atilgan et al., 2009). If the item discrimination index is 0.40 or higher, the item is classified as very good. If the index is between 0.30 and 0.39 , it is fair. If it is between 0.20 and 0.29 , the item should be revised and improved. If the index is between 0.00 and 0.19 , the item is poor and if it is not able to be revised, it should be excluded from the test. The item with index of 0.00 does not discriminate and must be excluded from the test because that means there is not any relationship between the item and the test.

The non-existence of the negative index of item discrimination on the items in the scale of problem solving proves that the existing items have measured what they were purposed to. In conclusion, as all the items in the present test were above 0.40 , which is the level for discrimination power, they did not need to be changed or revised. It was concluded that all the items differentiated between successful and unsuccessful students well.

It is seen in Table 5 that the total item correlations for all the items in the scale range between .20 and .63 and the $\mathrm{t}$ values are significant $(\mathrm{p}<.01)$. Considering these results, it can be said that all the items in the scale have excellent reliability $(0,60 \leq \alpha<0,80)$ and also, the items could discriminate the students in terms of their problemsolving skills.

Table 5. Reliability and total item correlations of the items in the SPSDH

\begin{tabular}{lccc}
\hline Item no & Cronbach Alpha & Item-total correlations & t (sub \%27-top \%27) \\
\hline $\mathrm{m} 1$ &, 629 &, 630 & $-5,34$ \\
\hline $\mathrm{m} 2$ &, 681 &, 343 & $-3,21$ \\
\hline $\mathrm{m} 3$ &, 638 &, 523 & $-10,38$ \\
\hline $\mathrm{m} 4$ &, 672 &, 385 & $-7,55$ \\
$\mathrm{~m} 5$ &, 647 &, 495 & $-6,66$ \\
$\mathrm{~m} 6$ &, 713 &, 208 & $-3,58$ \\
\hline $\mathrm{m} 7$ &, 706 &, 234 & $-3,15$ \\
\hline $\mathrm{m} 8$ &, 671 &, 390 & $-7,18$ \\
\hline
\end{tabular}

$\mathrm{N}=100 \mathrm{n} 1=\mathrm{n} 2=20 \mathrm{p}=<.01$

\section{DISCUSSION AND CONCLUSION}

It is important for an individual to improve the skills of data collecting and analysing in order to solve the problems they face and to achieve in life. It is vital to gain the problem solving skills to the people with impairment as well. WHO (2001) states that problem solving is an essential ability for a successful education and this skill can potentially be affected negatively by hearing impairment. Due to lack of experience (stimuli) and underdeveloped linguistic skills compared to their typical peers, individuals with hearing impairment often also have underdeveloped problem-solving skills. As the main objective of teaching is to make the students ready for the life by increasing their cognitive abilities, it is necessary to identify their problem-solving skills and eliminate the deficiencies. The existing scales of problem solving have generally been developed for people without impairment, which is why people with impairment have difficulty in understanding the statements and replying to them. When the studies carried out with deaf and hard-of-hearing people were examined, mathematical problems, word tests, games like "the Tower of Hanoi" and "20 Questions", and visual puzzles were observed mainly to be used to determine the problem-solving skills (Laurent, 2014; Marschark and Everhart, 1999; Mousley and Kelly, 1998). However, no inventory to measure these skills was encountered. So as to suggest a solution to the problem, in this study, the scale of problem-solving skills developed by Sezgin (2009) for primary school students without impairment was modified for deaf and hard-of-hearing students: verbal expressions were reduced, the problems were simplified and pictures were included accordingly.

In order to ensure the construct and content validity of the scale, expert opinion was referred to. The Scale of Problem Solving for The Deaf and Hard of Hearing (SPSDH) consisted of 8 items about figuring out experiences of a family of three people while planning a holiday together and which questions they needed to reply to in order to find a solution. While evaluating the responses, the right answer was scored with 1 and the wrong with 0 . With 
item analysis, average indices of item difficulty and discrimination of the test were calculated as 0.46 and 0.63 respectively. As all the items in the present test were above 0.40 which is the level for discrimination power, they did not need to be changed or revised. It was concluded that all the items differentiated between successful and unsuccessful students well.

The Kuder-Richardson formula 20 was used for estimating the reliability of thKR-20 internal consistency coefficient was .704 for 8 items according to the formula. This proved that the measurement tool explained the problem-solving skill with eight items by $70 \%$.

When the reliability and total item correlations of the items in the SPSDH are examined, it is seen that total item correlations for all the items in the scale range between .20 and .63 and $t$ values are significant $(p<.01)$. Considering these outcomes, it can be said that the items could discriminate the students in terms of their problemsolving skills.

As a conclusion, when the findings related to the determination of validity and reliability of the Scale of Problem Solving for The Deaf and Hard of Hearing (SPSDH) are assessed together, it is confirmed to be a valid and reliable measurement tool that might be used for identifying the problem-solving skills of secondary school-aged deaf and hard-of-hearing students. There are not many studies about the problem-solving skills of secondary school-aged students (Smiley et al., 2009). On the other hand, it is not possible to associate the scale developed in this research to the literature due to the fact that it is not fair to compare the studies regarding the problem-solving skills of the students with/without impairment because of the reasons suggested before. It can be inferred that the scale developed in consequence of the present research is a sufficient measurement tool to be applied in problem-solving studies on the deaf and hard of hearing.

\section{REFERENCES}

Atılgan, H., Kan, A. and Doğan, N. (2009). Measurement and evaluation in education (4th ed.). Ankara, Turkey: An1 Publishing.

Büyüköztürk, Ş. (2003). Sosyal Bilimler İ̧in Veri Analizi El Kitabı (Data Analysis Handbook for the Social Sciences). Ankara, Turkey: Pegem A publishing.

Gagne, R. M. (1980). The conditions of learning. NewYork: Holt, Rinehart, \& Winston, p 85.

Karal, Y. Şılbır, L., Bahçekapıll, E. and Atasoy, M. (2014). Learning materials based on graphic symbols for the hearing-impaired extended abstract. Journal of Instructional Technologies \& Teacher Education, 3(3).

Krulick, S. and Rudnick, J. A. (1988). Problem solving: A bandbook for elementary school teachers. Boston, USA: Allyn \& Bacon. Available at: http:/ / files.eric.ed.gov/fulltext/ED301459.pdf

Laurent, A. T. G. (2014). An analysis of the problem solving skills of children who are deaf or hard of hearing. Unpublished master thesis. Washington University School of Medicine in St. Louis. Available at: http:/ / digitalcommons.wustl.edu/cgi/viewcontent.cgi? article $=1688 \&$ context=pacs_capstones

Luckner, J. L. and McNeill, J. H. (1994). Performance of a group of deaf and hard-of-hearing students and a comparison group of hearing students on a series of problem-solving tasks. American Annals of the Deaf, 139(3), 371-377. https://doi.org/10.1353/aad.2012.0290 Project MUSE. Web. Available at: https://muse.jhu.edu/ (Accessed 24 June 2016).

Marschark, M. and Everhart, V. S. (1999). Problem-solving by deaf and hearing students: twenty questions. Deafness \& Education International, 1(2), 65-82. https://doi.org/10.1002/dei.48 Available at: http://onlinelibrary.wiley.com/doi/10.1002/dei.48/abstract

Marzano, R. J., Brandt, R. S., Hughes, C. S., Jones, B. F., Presseisen, B. Z., Rankin, S. C., et al. (1988). Dimensions of thinking: A framework. for curriculum and instruction. Alexandria, V. A: Association for Supervision and Curriculum Development. Available at: http://files.eric.ed.gov/fulltext/ED294222.pdf

Mousley, K. and Kelly, R. R. (1998). Problem-Solving Strategies for Teaching Mathematics to Deaf Students. American Annals of the Deaf, 143(4), 325-336. Available at: https://muse.jhu.edu/ https://doi.org/10.1353/aad.2012.0082

Sezgin, E. (2011). The improvement of the scale about problem solving skills. Unpublished Master Thesis, Ankara University, Turkey. Available at: http:/ /acikarsiv.ankara.edu.tr/browse/26928/tez.pdf

Smiley, D. F., Thelin J. W., Lance D. M. and Muenchen, R. A. (2009). Problem-solving ability in elementary schoolaged children with hearing impairment. Journal of Educational Audiology, 15, 28-38. Available at: http://www.edaud.org/journal/2009/3-article-09.pdf

Thornton, S. (1995). Children solving problems. Cambridge, MA: Harvard University Press 
Tüfekçioğlu, U. (2005). Çocuklarda işitme kaybının etkileri (The effects of hearing loss in children). U. Tüfekçioğlu (ed.), İsitme, konusma ve görme sorunu olan çocuklarn eğitimi (Cbildren's education that hearing, speech and vision problems) (s. 1-46) Eskişehir, Turkey: Publications of Anadolu University.

World Health Organization (WHO). (2001). ICF: International classification of functioning disability and health. Geneva: Author. Available at: http://www.who.int/classifications/icf/icf_more/en/

\section{APPENDIX}

\section{Scale of Problem Solving for the Deaf-Hard Hearing}

\section{Part I}

Ali and his family will go for a holiday. Let's find the date on which the family can go together. Red coloured days are good for mother and father.

When will they be able to go for two weeks holiday together?

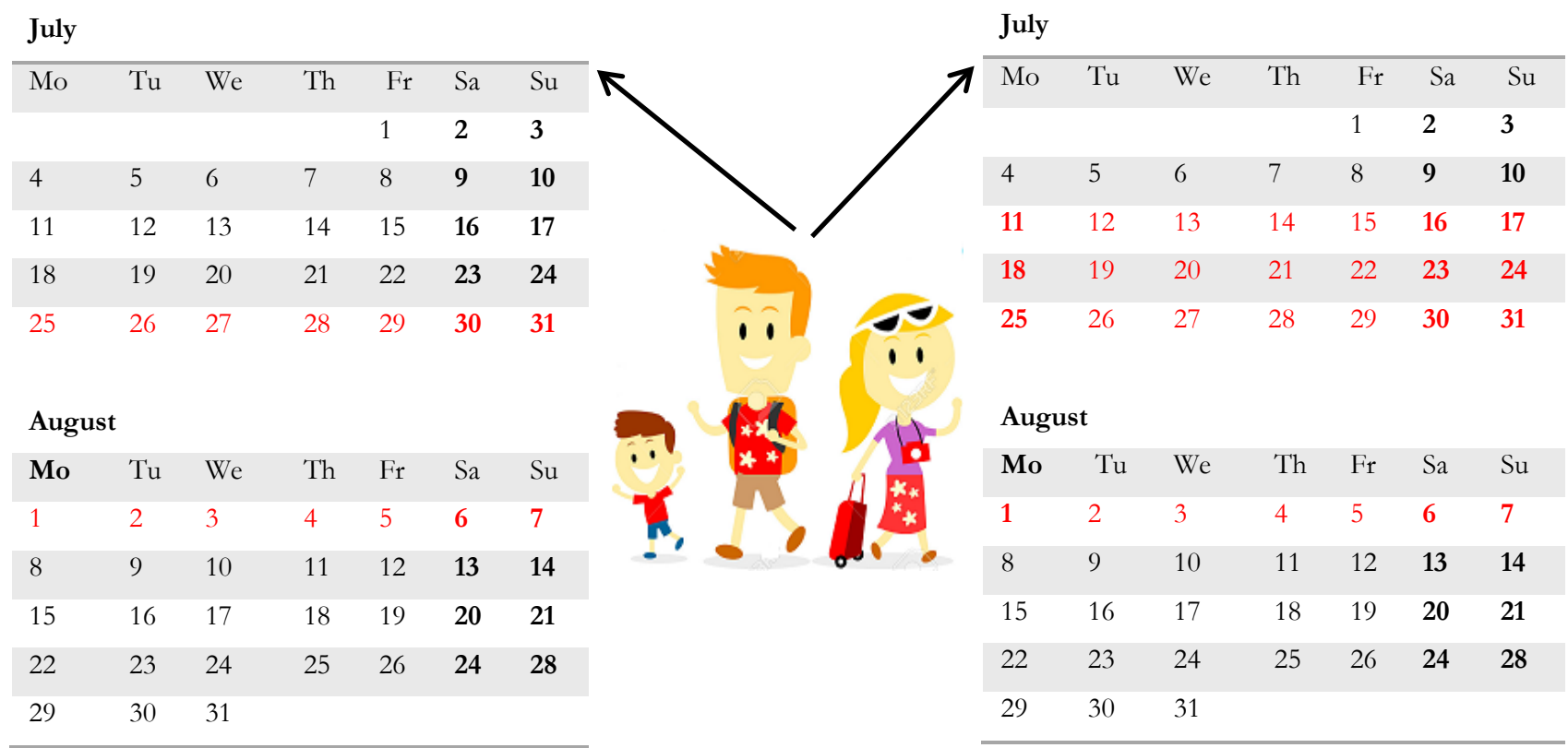

\section{Part II- Part III}

Where does the family want to go together?

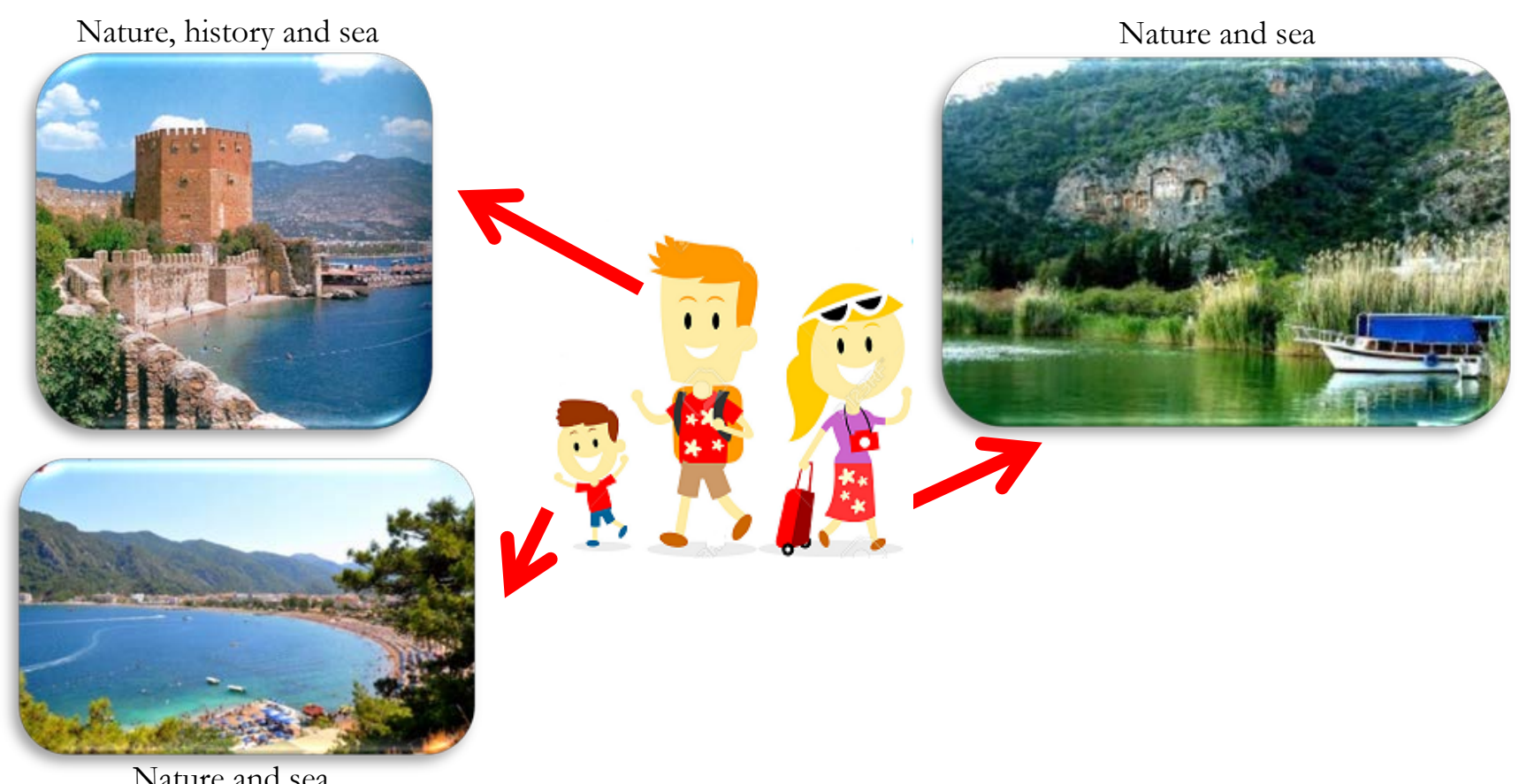

Nature and sea 
What is the problem of the family?

$\square$ How many people will go on holiday together

$\square$ Where and how will they have holiday

$\square$ Natural beauties and their historical significance

When will they have a holiday

\section{Part IV}

Table of Holiday Fares

\begin{tabular}{|l|l|}
\hline Travel name & Fare \\
\hline Star tour & 2500 \\
\hline Rack tour & 3000 \\
\hline Sun tour & 2400 \\
\hline
\end{tabular}

Which tour company did give the best price?

\section{Part V}

Return fares of the bus companies are given in the Table below:

\begin{tabular}{|c|c|}
\hline Bus & Fare \\
\hline 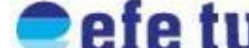 & $600 \mathrm{TL}$ \\
\hline ULUSOY & $550 \mathrm{TL}$ \\
\hline$M=\frac{2}{2 \pi}$ & $500 \mathrm{TL}$ \\
\hline
\end{tabular}

\section{Which of the following is correct?}

$\square$ Efe Tur's fare is cheaper than Ulusoy's

$\square$ The cheapest bus is Metro

$\square$ Ulusoy's fare is more expensive than Metro

\section{Part VI}

Ali's family paid 2400 TL for the holiday. Fare 2400:3=800

Tour company made a discount of $300 \mathrm{tl}$ as the family paid the fare in cash.

Which one is correct?
$300: 3=$
$300: 2=$

\section{Part VII}

Ali's family will go for holiday by car. They should fuel the car up. There is a way of $200 \mathrm{~km}$. How much should they fuel up? Which of the following sentences is correct?
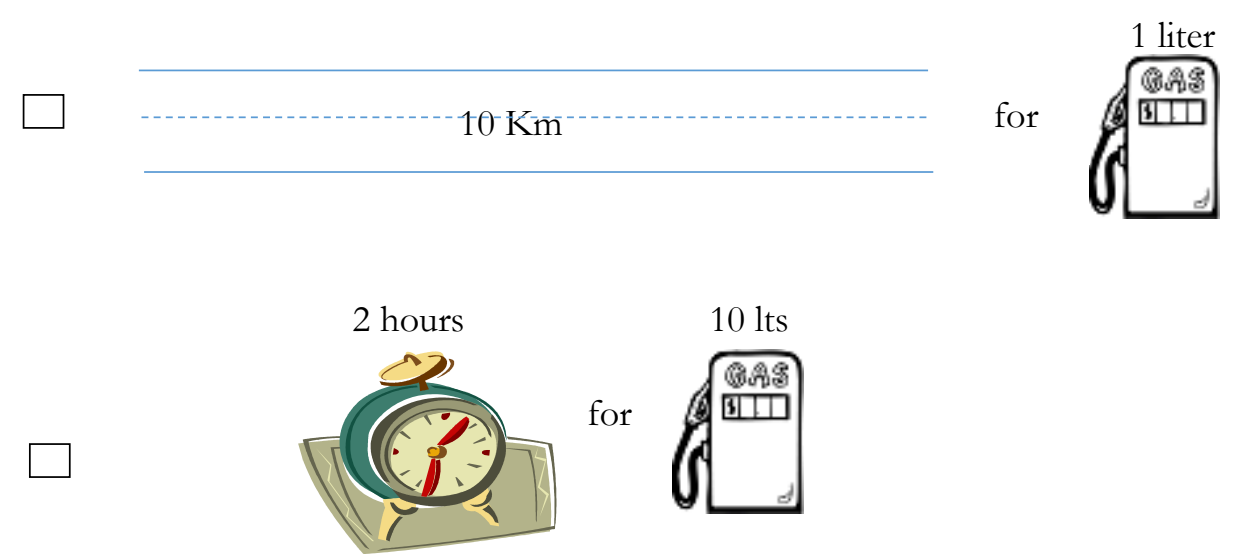
How much fuel is needed?

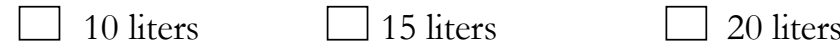

